\title{
Laboratory Research on Fracture-Supported Shielding Temporary Plugging Drill-In Fluid for Fractured and Fracture-Pore Type Reservoirs
}

\author{
Dawei Liu, ${ }^{1,2}$ Yili Kang, ${ }^{2}$ Quanwen Liu, ${ }^{1}$ Dengsheng Lei, ${ }^{3}$ and Bo Zhang' \\ ${ }^{1}$ Guangdong Provincial Key Laboratory of Petrochemical Equipment Fault Diagnosis, Guangdong University \\ of Petrochemical Technology, Maoming, Guangdong 525000, China \\ ${ }^{2}$ State Key Laboratory of Oil and Gas Reservoir Geology and Exploitation, Southwest Petroleum University, Chengdu, \\ Sichuan 610500, China \\ ${ }^{3}$ Chongqing University of Science \& Technology, Chongqing 401331, China
}

Correspondence should be addressed to Dawei Liu; ldw2278@163.com

Received 16 November 2016; Revised 3 January 2017; Accepted 13 February 2017; Published 13 March 2017

Academic Editor: Achinta Bera

Copyright ( 92017 Dawei Liu et al. This is an open access article distributed under the Creative Commons Attribution License, which permits unrestricted use, distribution, and reproduction in any medium, provided the original work is properly cited.

Based on fractures stress sensitivity, this paper experimentally studies fracture-supported shielding temporary plugging drill-in fluid (FSDIF) in order to protect fractured and fracture-pore type formation. Experimental results show the FSDIF was better than the CDIF for protecting fractured and fracture-pore type reservoir and the FSDIF temporary plugging rate was above $99 \%$, temporary plugging ring strength was greater than $15 \mathrm{MPa}$, and return permeability was $91.35 \%$ and $120.83 \%$ before and after acidizing, respectively. The reasons for the better reservoir protection effect were analyzed. Theoretical and experiment studies conducted indicated that the FSDIF contained acid-soluble and non-acid-soluble temporary shielding agents; non-acid-soluble temporary shielding agents had high hardness and temporary plugging particles size was matched to the formation fracture width and pore throat size.

\section{Introduction}

A fractured reservoir is a reservoir in which the fractures act as the main reservoir space and seepage channel. A fracture-pore type reservoir is a reservoir in which the pore acts as the main reservoir space and fractures are the main seepage channel [1]. Fractured and fracture-pore type reservoirs, such as carbonate reservoirs, are characterized by heterogeneous natural fractures with strong stress sensitivity, a large dynamic width range, and vulnerability to damage $[2,3]$. Shielding temporary plugging technology has been widely used to protect such reservoirs when the reservoir is drilled. This technique, using the pressure difference between the drilling fluid and reservoir, forces the drilling fluids that intentionally added various types and sizes of solid particles into the pore throat or fracture stenosis in a very short period of time. This leads to the formation of a shielding temporary plugging ring near the wellbore and permeability close to zero. Thus, the shielding temporary plugging ring effectively prevents the drilling fluid and subsequent construction damage to the reservoir continually. Finally, the use of perforation or other methods unblocks the shielding temporary plugging ring to recover the reservoir permeability [4]. Shielding temporary plugging in low-, medium-, and high-permeability pore reservoirs already works well; however, there is still considerable room for improvement in the temporary plugging of fractured and fracture-pore type reservoirs. The main problems are fractures strong stress sensitivity, and low return permeability of the filter cake after natural flowback and chemical break down [5-13]. Therefore, it is important to develop a kind of shielding temporary plugging drill-in fluid system with a high temporary plugging rate and return permeability for the fractured and fracturepore type reservoirs. The temporary plugging rate is the ratio of the permeability after shielding ring formation to the original rock permeability in units of $\%$. The higher the 
TABLE 1: Physical properties of the rock samples.

\begin{tabular}{|c|c|c|c|c|c|c|}
\hline Rock samples & Stratum & Length $(\mathrm{cm})$ & Diameter $(\mathrm{cm})$ & Porosity (\%) & Water permeability $\left(10^{-3} \mu \mathrm{m}^{2}\right)$ & Remarks \\
\hline $1 \#$ & $\mathrm{P}_{2} \mathrm{ch}$ & 4.540 & 2.53 & 5.05 & 731.89 & Fracture \\
\hline 2\# & $\mathrm{P}_{2} \mathrm{ch}$ & 5.742 & 2.51 & 10.30 & 27.45 & Fracture \\
\hline 3\# & $\mathrm{T}_{1} \mathrm{f}$ & 4.620 & 2.52 & 13.61 & 34.22 & Block \\
\hline
\end{tabular}

TABLE 2: Experimental FSDIF properties.

\begin{tabular}{lccccccc}
\hline$\rho\left(\mathrm{g} / \mathrm{cm}^{3}\right)$ & $\mathrm{pH}$ & $\mathrm{FL}(\mathrm{ml})$ & $K(\mathrm{~mm})$ & $\mathrm{Q}_{3}{ }^{10^{\prime \prime}} / \mathrm{Q}_{3}{ }^{10^{\prime}}(\mathrm{Pa})$ & $\mathrm{AV}(\mathrm{mPa} \cdot \mathrm{s})$ & $\mathrm{PV}(\mathrm{mPa} \cdot \mathrm{s})$ & $\mathrm{YP}(\mathrm{MPa} \cdot \mathrm{s})$ \\
\hline 1.58 & 10 & 1.8 & 0.3 & $2 / 5.5$ & 57 & 47 & 10.3 \\
\hline
\end{tabular}

temporary plugging rate, the lower the permeability of the shielding ring and the more it prevented the invasion of the drilling fluid and subsequent construction damage to the reservoir. In this work, experiments were carried out on integrated acid-soluble and non-acid-soluble temporary plugging agents of fracture-supported drill-in fluid (FSDIF) protecting reservoirs, and the FSDIF for fractured and fractured-pore type reservoirs was analyzed with a better temporary plugging effect mechanism.

\section{Experimental Materials and Methods}

\subsection{Temporary Plugging Flowback Performance Test}

2.1.1. Drill-In Fluid Formulation. The FSDIF formulation was as follows: base mud $+3 \%$ filtrate loss reducer $+3 \%$ lubricant agent $+6 \%$ weighting agent $+0.5 \%$ viscosity reducer $+3 \%$ formation protective agent $+2 \%$ proppant agent.

The CDIF formulation was as follows: base mud $+3 \%$ filtrate loss reducer $+3 \%$ lubricant agent $+6 \%$ weighting agent + $0.5 \%$ viscosity reducer $+3 \%$ formation protective agent.

2.1.2. Experimental Rock Samples. Carbonate rock samples from the Changxing group (2 pieces) and Feixianguan group (1 piece) with different permeability levels were used. Fracture samples were confined under a pressure of $30 \mathrm{MPa}$ for 20 minutes. The physical parameters of the rocks are shown in Table 1. The FSDIF and CDIF were added with and without the proppant, respectively. Other formulations were the same. The only different performance was the FSDIF being larger $0.01 \mathrm{~g} / \mathrm{cm}^{3}$ than CDIF in density and the performance of FSDIF is shown in Table 2.

The instruments used to study the FSDIF properties included a six speed rotary viscometer, middle pressure tester, density meter, and an automatic measuring instrument for filter cake thickness and toughness. The test methods are detailed in the People's Republic of China Petroleum and Natural Gas Industries Standards (GB/T16783.1-2014).

2.1.3. Experimental Methods. The acidification filter cake clean-up method was performed as follows: (1) The temporary plugging rate was determined, and the temporary plugging effect was analyzed using the experiment method of temporary plugging and natural flowback detailed in literature [14]. (2) The filter cake was treated with hydrochloric acid, and then forward formation water derived (flowback); find out breakthrough pressure of the filer cake Pd and record flowback pressure $P_{i}$ and the permeability of rock samples $K_{w i}$, calculate rock's return $K_{f}=K_{w i} / K w \times 100 \%$, increased differential pressure of flowback, and calculate the $K_{f}$.

2.2. Temporary Plugging Strength Experiment. The same shielding temporary plugging drill-in fluid was used as in Section 2.1.1, and the experimental methods used to determine the temporary plugging strength are detailed in literature [15].

The fracture rock samples used were artificial fracture samples. Before the experiment, fracture rock was confined under a pressure of $30 \mathrm{MPa}$ for $20 \mathrm{~min}$. The physical properties of some samples are shown in Table 3.

\section{Experimental Results}

3.1. Temporary Plugging and Flowback Performance Test. Experimental results are shown in Table 4 and Figure 1. The FSDIF temporary plugging rate $\mathrm{Zd}$ on base block and fracture rock was greater than the expected temporary plugging rate, and the loss of drill-in fluid was less than $1 \mathrm{ml}$ within 1 hour, which showed that the FSDIF had a better temporary plugging effect. After natural flowback at a pressure of $1 \mathrm{MPa}$, the highest return permeability of the rock samples reached $91.35 \%$, the average being $90.42 \%$. The return permeability of the fractured rock samples was lower than that of the base block rock samples.

Acidification was an effective measure to remove the filter cake damage in the carbonate reservoir. Therefore, in order to improve the return permeability of the rock samples, the filter cake was removed by hydrochloric acid and the return permeability of the CDIF was compared with that of the FSDIF. As shown in Table 5 and Figure 2, the return permeability of all the rock samples after acidification, determined by a flow pressure of $0.5 \mathrm{MPa}$, improved significantly up to $120.83 \%$ (as shown in Table 5 for rock sample 2\#).

The FSDIF showed obvious advantages over the CDIF such as a significant increase in return permeability of fracture rock samples after acidification.

3.2. Temporary Plugging Strength Test. In forming the carbonate rock, the same open hole section often had both high and low-pressure layers. Loss of circulation was encountered 
TABLE 3: Physical properties of rock samples.

\begin{tabular}{|c|c|c|c|c|c|c|}
\hline Rock samples & Stratum & Length $(\mathrm{cm})$ & Diameter $(\mathrm{cm})$ & Porosity (\%) & Water permeability $\left(10^{-3} \mu \mathrm{m}^{2}\right)$ & Remarks \\
\hline $4 \#$ & $\mathrm{~T}_{1} \mathrm{f}$ & 3.592 & 2.520 & 10.470 & 349.000 & Block \\
\hline $5 \#$ & $\mathrm{~T}_{1} \mathrm{f}$ & 3.576 & 2.530 & 9.910 & 311.000 & Block \\
\hline 6\# & $\mathrm{T}_{1} \mathrm{f}$ & 5.334 & 2.560 & 9.300 & 0.214 & Fracture \\
\hline 7\# & $\mathrm{T}_{1} \mathrm{f}$ & 7.278 & 2.558 & 11.037 & 0.073 & Fracture \\
\hline
\end{tabular}

TABLE 4: Evaluation results of the temporary plugging performance of the shielding ring.

\begin{tabular}{|c|c|c|c|c|c|c|c|c|c|}
\hline \multirow{2}{*}{\multicolumn{2}{|c|}{ Rock samples Stratum }} & \multirow{2}{*}{ Fractures width $(\mu \mathrm{m})$} & \multicolumn{4}{|c|}{$T(\min ) / F_{l}(\mathrm{ml})$} & \multirow{2}{*}{$\begin{array}{c}T(\min ) / \mathrm{Zd}(\%) \\
15\end{array}$} & \multirow{2}{*}{ Expected temporary plugging rate (\%) } & \multirow{2}{*}{ Remarks } \\
\hline & & & 7.5 & 15 & 30 & 60 & & & \\
\hline $1 \#$ & $\mathrm{P}_{2} \mathrm{ch}$ & 61.1 & 0.18 & 0.18 & 0.21 & 0.22 & 100 & 99.94 & Fracture \\
\hline 2\# & $\mathrm{P}_{2} \mathrm{ch}$ & 20.3 & 0.15 & 0.44 & 0.58 & 0.58 & 99.86 & 98.39 & Fracture \\
\hline 3\# & $\mathrm{T}_{1} \mathrm{f}$ & - & 0.07 & 0.27 & 0.31 & 0.35 & 99.71 & 98.72 & Block \\
\hline
\end{tabular}

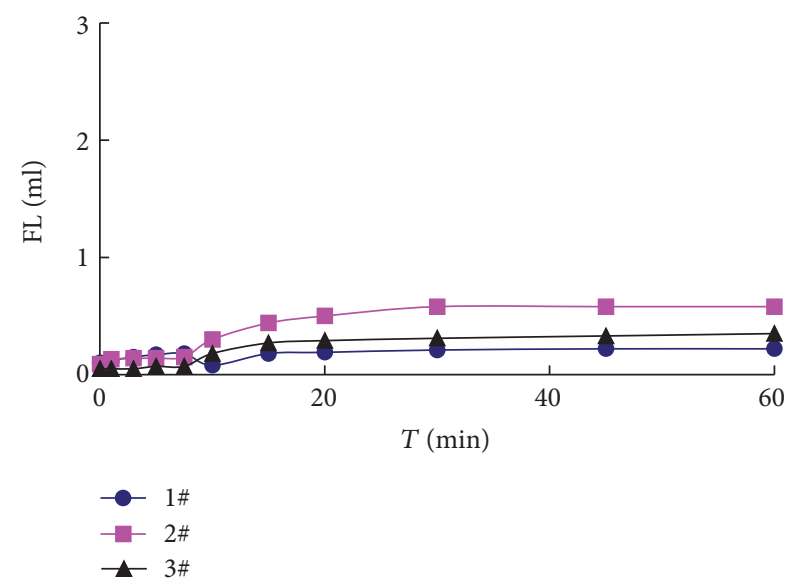

FIGURE 1: The relationship between drill-in fluid loss and time after the formation of shielding ring.

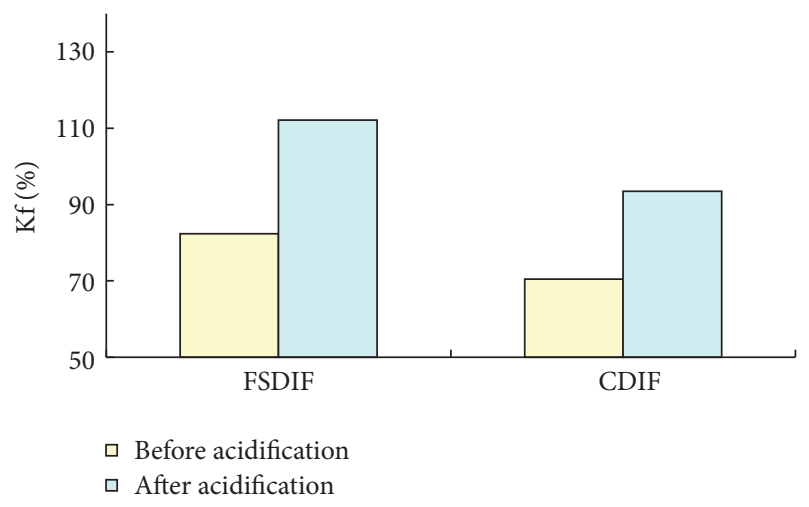

Figure 2: Performance comparison of the CDIF and FSDIF.

in the low-pressure layers when the high pressure layers were drilling. Therefore, the bearing capacity of this kind of easy leakage formation must be considered [16-21]. In addition, there must be a larger pressure difference to ensure

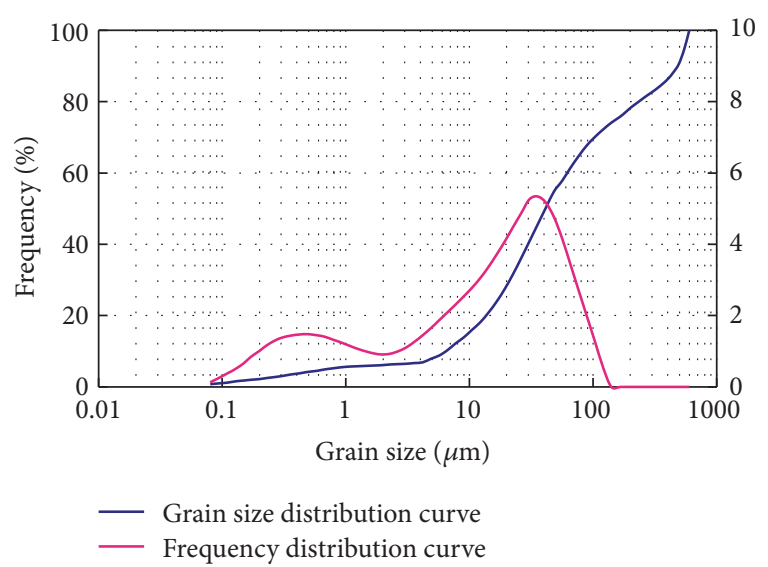

FIGURE 3: Grain size distribution curve of the FSDIF.

highly efficient cementation; thus, it was necessary to test the temporary plugging strength of the filter cake during drilling and other operations.

The RTR-100 triaxial rock mechanics-testing system was used to measure the strength of the shield ring formed using the FSDIF and it was compared with the temporary plugging strength of the CDIF. Experimental results are shown in Table 6. The temporary plugging strength of a shield ring formed by two kinds of drill-in fluid was at $25 \mathrm{MPa}$ or more, and the temporary plugging strength of the fracture rock samples shielding ring was lower. In general, the strength of the FSDIF shield ring was greater than that of the CDIF.

\section{Discussion}

4.1. Temporary Plugging Particles and Pore Throat/Fracture Matching Relationship. Figure 3 shows a grain size curve of the FSDIF. The grain size of the drill-in fluid was mainly distributed in the range 3-150 $\mu \mathrm{m}$, with a grain size peak seen in the range of $20-60 \mu \mathrm{m}$. The experimental fracture width of the samples was between 20 and $60 \mu \mathrm{m}$ and contributed to the permeability of the base block rock pore throat diameter 


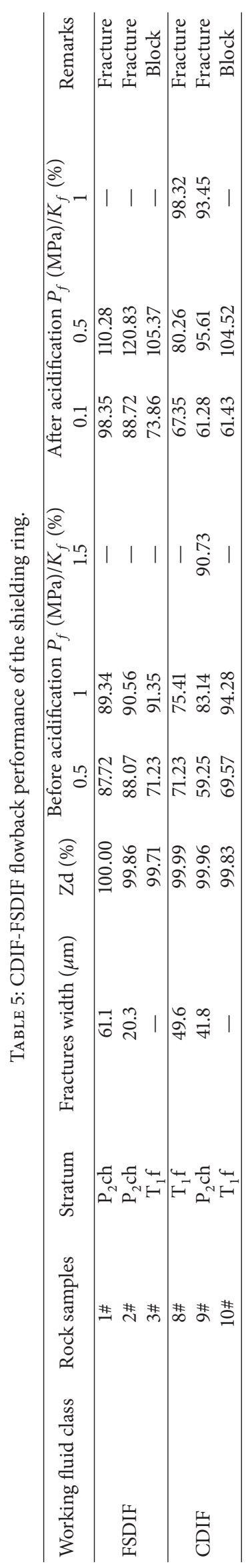


TABLE 6: Table contrasting the shielding ring strength of the CDIF and FSDIF.

\begin{tabular}{|c|c|c|c|c|c|c|c|c|}
\hline Working fluid class & Rock samples & Stratum & $\mathrm{Zd}(\%)$ & $\Delta p(\mathrm{MPa})$ & $P(\mathrm{MPa})$ & $T(\min )$ & Click through time statistics & Remarks \\
\hline \multirow{7}{*}{ FSDIF } & \multirow{4}{*}{$5 \#$} & \multirow{4}{*}{$\mathrm{T}_{1} \mathrm{f}$} & \multirow{4}{*}{100.00} & \multirow{4}{*}{17.5} & \multirow{4}{*}{35} & \multirow{4}{*}{130} & $30 \mathrm{~min} / 20 \mathrm{MPa}$ & \multirow{4}{*}{ Block } \\
\hline & & & & & & & $30 \mathrm{~min} / 25 \mathrm{MPa}$ & \\
\hline & & & & & & & $30 \mathrm{~min} / 30 \mathrm{MPa}$ & \\
\hline & & & & & & & $40 \mathrm{~min} / 35 \mathrm{MPa}$ & \\
\hline & \multirow{3}{*}{ 7\# } & \multirow{3}{*}{$\mathrm{T}_{1} \mathrm{f}$} & \multirow{3}{*}{99.86} & \multirow{3}{*}{17.5} & \multirow{3}{*}{30} & \multirow{3}{*}{83} & $30 \mathrm{~min} / 20 \mathrm{MPa}$ & \multirow{3}{*}{ Fracture } \\
\hline & & & & & & & $30 \mathrm{~min} / 25 \mathrm{MPa}$ & \\
\hline & & & & & & & $23 \mathrm{~min} / 30 \mathrm{MPa}$ & \\
\hline \multirow{5}{*}{ CDIF } & \multirow{2}{*}{$6 \#$} & \multirow{2}{*}{$\mathrm{T}_{1} \mathrm{f}$} & \multirow{2}{*}{99.99} & \multirow{2}{*}{17.5} & \multirow{2}{*}{25} & \multirow{2}{*}{47} & $30 \mathrm{~min} / 20 \mathrm{MPa}$ & \multirow{2}{*}{ Fracture } \\
\hline & & & & & & & $17 \mathrm{~min} / 25 \mathrm{MPa}$ & \\
\hline & \multirow{3}{*}{$4 \#$} & \multirow{3}{*}{$\mathrm{T}_{1} \mathrm{f}$} & \multirow{3}{*}{99.96} & \multirow{3}{*}{17.5} & \multirow{3}{*}{30} & \multirow{3}{*}{86} & $30 \mathrm{~min} / 20 \mathrm{MPa}$ & \multirow{3}{*}{ Block } \\
\hline & & & & & & & $30 \mathrm{~min} / 25 \mathrm{MPa}$ & \\
\hline & & & & & & & $26 \mathrm{~min} / 30 \mathrm{MPa}$ & \\
\hline
\end{tabular}

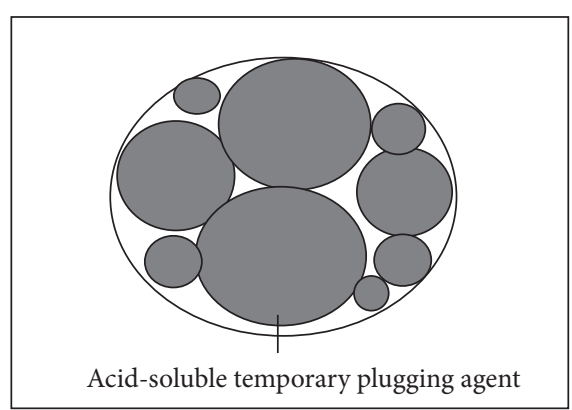

(a) Before acidification

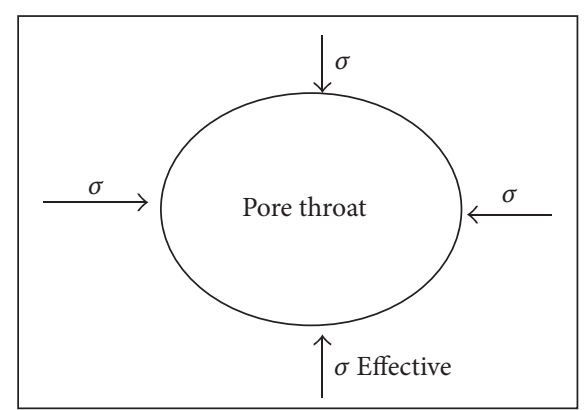

(b) After acidification

FIGURE 4: Pore throat characteristics before and after dissolution of the temporary plugging agent in acid.

ranging from 10 to $150 \mu \mathrm{m}$. This matched the size of the solid grains in the drill-in fluid, and fine particle-filled components and deformable particles were also present with sizes of $1-10 \mu \mathrm{m}$. These particles just filled the space formed by the bridging particle, which was conducive to the rapid formation of the shielding ring. When the solid particle size and rock pore throat diameter/fracture width match, solid and liquid invasion will be relatively shallow and temporary plugging rate will be higher [22, 23].

4.2. Effect of Stress Sensitivity on the Return Permeability of the Reservoir. Table 5 shows that, irrespective of whether the acidification removed the CDIF filter cake, after the flowback, return permeability of the fracture rock samples was significantly lower than the return permeability of the base block rock samples. The stress sensitivity was one of the most important factors affecting the return permeability. As shown in Figure 4, after acidification, acid-soluble temporary plugging material was corroded, and the pore throat changed little under the effective stress [24]. Therefore, after the filter cake was removed by acidification, the return permeability of the pore type reservoir was very high. Since the fracture of the reservoirs had strong stress sensitivity and acid-dissolved temporary plugging material, the fractures reduced to a line under the effective stress as shown in Figure 5. Therefore, after removal of the filter cake, the percolation ability of the fractured and fracture-pore type reservoir was not more easily recoverable.

Compared to the CDIF, the FSDIF could significantly improve the return permeability of fracture rock samples after acidification. Since the FSDIF added a certain amount of non-acid-soluble ceramsite, the grain size and fracture width matched. As shown in Figure 6, in drilling and completion operations (represented in the temporary plugging test), the ceramsite played a role in the bridging of temporary plugging and in production operations (represented in the flowback and acidification experiments) the proppant prevented the fracture from closing and, at the same time, allowed the acidsoluble temporary plugging particles to more easily flow back along the shore-up fracture channel. Therefore, the FSDIF return permeability increased significantly after acid defuse plugging.

4.3. Hardness of Temporary Plugging Particles and the Strength of the Shielding Ring. Figure 7 shows the strength contrast of the drill-in fluid filter cake consisting of quartz, calcium carbonate, and feldspar. It is seen that the crushing pressure of the filter cake increased with an increase in material strength. 


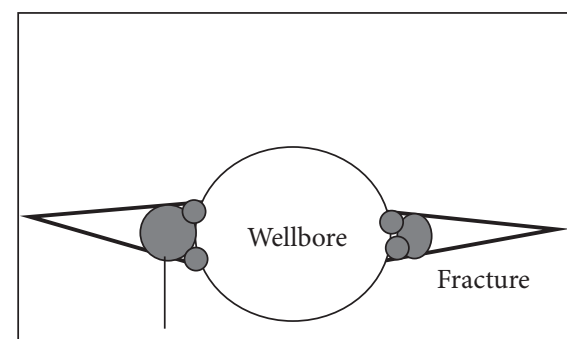

Acid-soluble temporary plugging agent

(a) Before acidification

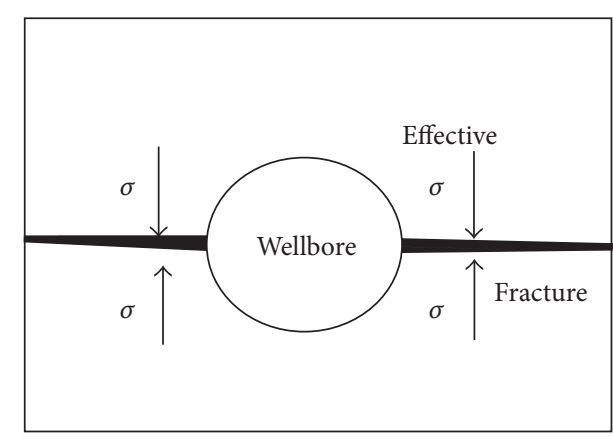

(b) After acidification

FIGURE 5: Fracture characteristics before and after dissolution of the temporary plugging agent in acid.

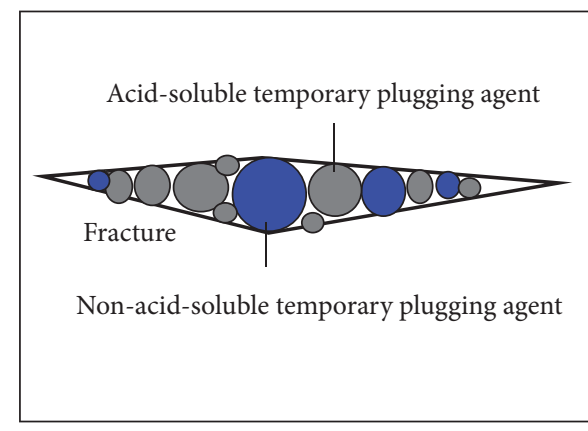

(a) Before acidification

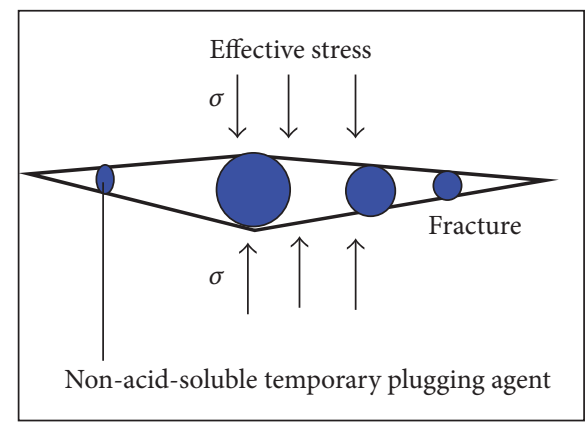

(b) After acidification

FIGURE 6: Fracture profile characteristics before and after the addition of an integrated temporary plugging agent.

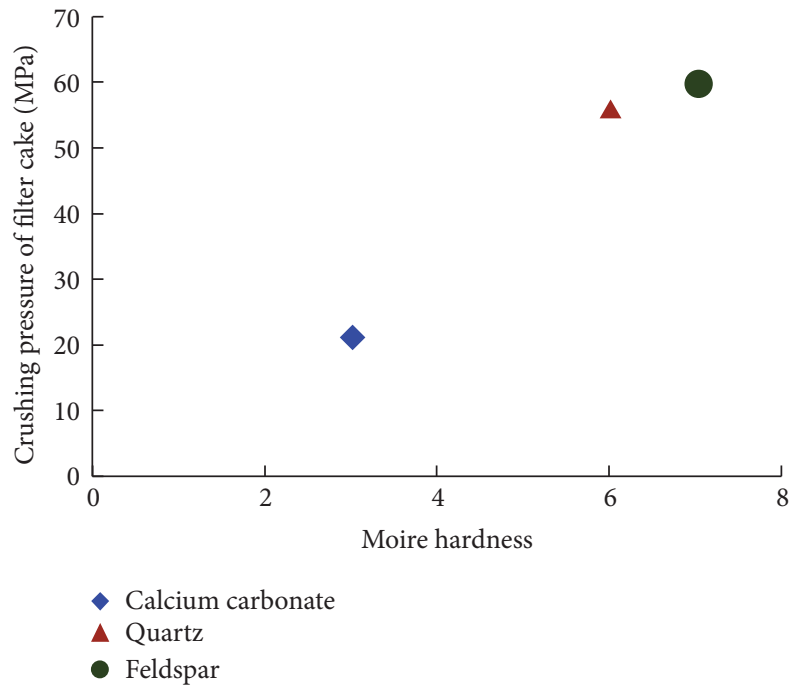

FIGURE 7: Strength of the filter cake formed by materials with different hardness (strengths) (according to Aadnoy et al., 2007).

Therefore, the filter cake consisted of quartz, the crushing pressure was maximum, and the hardness was maximum.

The FSDIF could effectively block off fracture and it also has higher strength. The FSDIF added the ceramsite whose strength was higher than that of ultrafine $\mathrm{CaCO}_{3}$ added by the CDIF and at the same time the sphericity of ceramsite increased to more than $99 \%$, which is much higher than the sphericity of superfine $\mathrm{CaCO}_{3}$. With high sphericity and strength of the FSDIF temporary plugging particles, the formation of the shield ring strength will also be higher [25].

\section{Conclusions}

(1) The strong stress sensitivity of fracture was the main reason for the low return permeability of fractured and fracture-pore type reservoirs. Pure acid-soluble temporary plugging agents for the protection of fractured and fracturepore type reservoirs were not ideal.

(2) Integrated acid-soluble and non-acid-soluble temporary plugging agents of FSDIF exhibited a good temporary plugging effect and return permeability. The temporary plugging rate was $99.5 \%$, the filter cake could bear at least the positive differential pressure of $15 \mathrm{MPa}$, and the return permeability of the rock samples was $90.42 \%$ on average, while the fracture rock return permeability was lower than the base rock samples.

(3) The non-acid-soluble temporary plugging agent was able to support fractures during filter cake removal, to prevent fractures closing, and to reduce the stress sensitivity of the fractured and fracture-pore type reservoirs. This was 
the main reason for the better protection of fractured and fracture-pore type reservoir by FSDIF with integrated acidsoluble and non-acid-soluble temporary plugging agents.

\section{Nomenclature}

$\begin{array}{ll}\rho: & \text { Density }\left(\mathrm{g} / \mathrm{cm}^{3}\right) \\ \mathrm{pH}: & \text { Degree of acidity and alkalinity } \\ \mathrm{FL}: & \text { Loss of water }(\mathrm{ml}) \\ K: & \text { Filter cake thickness }(\mathrm{mm}) \\ \mathrm{Q}_{3}{ }^{10^{\prime \prime}}: & \text { Initial shear stress }(\mathrm{Pa}) \\ \mathrm{Q}_{3}{ }^{10^{\prime}}: & \text { Ultimate shear }(\mathrm{Pa}) \\ \mathrm{AV}: & \text { Apparent viscosity }(\mathrm{mPa} \cdot \mathrm{s}) \\ \mathrm{PV}: & \text { Plastic viscosity }(\mathrm{mPa} \cdot \mathrm{s}) \\ \mathrm{YP}: & \text { Yield point }(\mathrm{Pa}) \\ P_{f}: & \text { Flowback pressure difference }(\mathrm{MPa}) \\ K_{f}: & \text { Return permeability }(\%) \\ Z_{d}: & \text { Temporary plugging rate }(\%) \\ \Delta p: & \text { Differential pressure }(\mathrm{MPa}) \\ P: & \text { Pressure }(\mathrm{MPa}) \\ T: & \text { Time (min) } \\ K w: & \text { Water permeability }(\mathrm{mD}) .\end{array}$

\section{Competing Interests}

The authors declare that there are no competing interests regarding the publication of this paper.

\section{Acknowledgments}

The authors wish to acknowledge that this work was supported by the Natural Science Foundation of the Guangdong Province "study on the mechanism of multiscale mass transfer in coalbed methane damage with fluid damage in the well" (no. 2016A030307024), the Opening Foundation of the Guangdong Provincial in the China Key Laboratory of Petrochemical Equipment Fault Diagnosis "corrosion mechanism and corrosion inhibitor of carbon dioxide in oil and gas wells" (no. GDUPTKLAB201603), the Opening Foundation of Maoming in the China Petrochemical Corrosion and Safety Engineering Technology Research and Development Center "corrosion behavior of oil and gas well pipe under HTHP and concentration of $\mathrm{CO}_{2}$ medium" (no. 660011), College Students Innovation and Entrepreneurship Project "design and degradation performance study of CBMrecycled microbubbles drill-in fluid” (no. 201511656008), and the Chongqing foundation and advanced research project (no. cstc2015jcyjA90022).

\section{References}

[1] J. Gu, Y.-G. Zhang, Y.-T. Gao, T.-F. Li, and X. Liu, "Protective methods, techniques and technologies and drilling/completion fluids for fractured reservoirs," Oilfield Chemistry, vol. 24, no. 1, pp. 87-92, 2007.

[2] Y. Kang, L. You, X. Xu, and Z. Liao, "Practices of formation damage control for deep fractured tight gas reservoir in western Sichuan basin," in Proceedings of the International Oil and Gas
Conference and Exhibition in China: Opportunities and Challenges in a Volatile Environment (IOGCEC '10), pp. 1665-1673, Beijing, China, June 2010.

[3] S. Benaissa, A. Bachelot, and S. Ong, "Preventing mud losses and differential sticking by altering effective stress of depleted sands," in Proceedings of the IADC/SPE Asia Pacific Drilling Technology Conference-Meeting the Value Challenge: Performance, Deliverability and Cost, pp. 396-405, IADC/SPE, Bangkok, Thailand, November 2006.

[4] P.-Y. Luo, "Shielding temporary plugging technology for protecting oil layer in drilling and completion process," in China National Petroleum Company Academy Collection, Academician of Chinese Academy of Engineering-Luo Pingya, pp. 68-98, Encyclopedia of China Publishing House, Beijing, China, 1997.

[5] D.-W. Liu, L.-J. You, M. Lei et al., "Research progresses in temporary plugging technology for carbonate reservoir protection," Drilling Fluid \& Completion Fluid, vol. 2, no. 5, pp. 57-61, 2008.

[6] G. F. Oluyemi, "Investigation of depletion induced formation damage mechanisms in fractured reservoirs," in Proceedings of the 9th European Formation Damage Conference, pp. 634-638, Noordwijk, The Netherlands, June 2011.

[7] C.-Y. Xu, Y.-L. Kang, D.-Q. Li et al., "Mathematical model and experimental study on drill-in fluid loss control and formation damage prevention in fractured tight reservoir," in Proceedings of the Asia Pacific Oil \& Gas Conference and Exhibition, SPE 182266-MS, Perth, Australia, October 2016.

[8] F. E. Dupriest, "Fracture closure stress (FCS) and lost returns practice," in Proceedings of the SPE/IADC Drilling Conference, SPE 92192, Amsterdam, The Netherlands, February 2005.

[9] Y. L. Kang, L. J. You, X. Xu, and Z. Liao, "Prevention of formation damage induced by mud lost in deep fractured tight gas reservoir in western Sichuan basin," Journal of Canadian Petroleum Technology, vol. 51, no. 1, pp. 46-51, 2012.

[10] Y. Kang, C. Xu, L. You, H. Yu, and D. Zhang, “Temporary sealing technology to control formation damage induced by drill-in fluid loss in fractured tight gas reservoir," Journal of Natural Gas Science and Engineering, vol. 20, pp. 67-73, 2014.

[11] Y.-L. Kang, C.-Y. Xu, L. Tang, S. Li, and D.-Q. Li, "Constructing a tough shield around the wellbore: theory and method for lostcirculation control," Petroleum Exploration and Development, vol. 41, no. 4, pp. 473-479, 2014.

[12] Y.-L. Kang, C.-Y. Xu, L.-J. You, H.-F. Yu, and B.-J. Zhang, "Comprehensive evaluation of formation damage induced by working fluid loss in fractured tight gas reservoir," Journal of Natural Gas Science and Engineering, vol. 18, pp. 353-359, 2014.

[13] Y.-L. Kang, C.-Y. Xu, L.-J. You, and H.-H. Yu, "An optimal design for millimeter-wide facture plugged zone," Natural Gas Industry B, vol. 7, no. 3, pp. 1-7, 2015.

[14] J. Liu, Y.-L. Kang, and D.-W. Liu, "Research on temporary shielding plugging experiment in considering fracture-pore reservoir of fracture width and pressure difference," Drilling \& Production Technology, vol. 29, no. 2, pp. 97-101, 2006.

[15] F. Zhao, H.-M. Tang, Y.-F. Meng, H.-M. Xu, and X.-Y. Xie, "Research on the determination of the strengths of the mud cakes formed by temporary bridging and plugging agents," Drilling Fluid and Completion Fluid, vol. 24, no. 2, pp. 29-31, 2007.

[16] A. Kumar, S. Savari, D. Whitfill, and D. E. Jamison, "Wellbore strengthening: the less-studied properties of lost-circulation materials," in Proceedings of the SPE Annual Technical Conference and Exhibition, SPE 133484, Florence, Italy, September 2010. 
[17] E. Van Oort, J. Friedheim, T. Pierce, and J. Lee, "Avoiding losses in depleted and weak zones by constantly strengthening wellbores," SPE Drilling and Completion, vol. 26, no. 4, pp. 519530, 2011.

[18] H. Wang, M. Y. Soliman, and B. F. Towler, "Investigation of factors for strengthening a wellbore by propping fractures," SPE Drilling and Completion, vol. 24, no. 3, pp. 441-451, 2009.

[19] N. Morita and G.-F. Fuh, "Parametric analysis of wellborestrengthening methods from basic rock mechanics," SPE Drilling and Completion, vol. 27, no. 2, pp. 315-327, 2012.

[20] M. P. Shahri, T. T. Oar, R. Safari, M. Karimi, and U. Mutlu, "Advanced semianalytical geomechanical model for wellborestrengthening applications," SPE Journal, vol. 20, no. 6, pp. 12761286, 2015.

[21] A. Kalantariasl and P. Bedrikovetsky, "Stabilization of external filter cake by colloidal forces in a "well-reservoir" system," Industrial and Engineering Chemistry Research, vol. 53, no. 2, pp. 930-944, 2014.

[22] A. Kalantariasl, R. Farajzadeh, Z. You, and P. Bedrikovetsky, "Nonuniform external filter cake in long injection wells," Industrial and Engineering Chemistry Research, vol. 54, no. 11, pp. 3051-3061, 2015.

[23] R. N. Sacramento, Y. Yang, Z. You et al., "Deep bed and cake filtration of two-size particle suspension in porous media," Journal of Petroleum Science and Engineering, vol. 126, no. 1, pp. 201-210, 2015.

[24] J. He, Y.-L. Kang, D.-W. Liu, M. Lei, and Z.-Z. Shu, "The stress sensitivity research on porous and fractured porous carbonate reservoirs," Drilling and Production Technology, vol. 28, no. 2, pp. 6-93, 2005.

[25] B. S. Aadnoy, M. Arriado, and R. Flateboe, "Design of well barriers to combat circulation losses," in Proceedings of the SPE/ IADC Drilling Conference, SPE105449-MS, Amsterdam, The Netherlands, February 2007. 

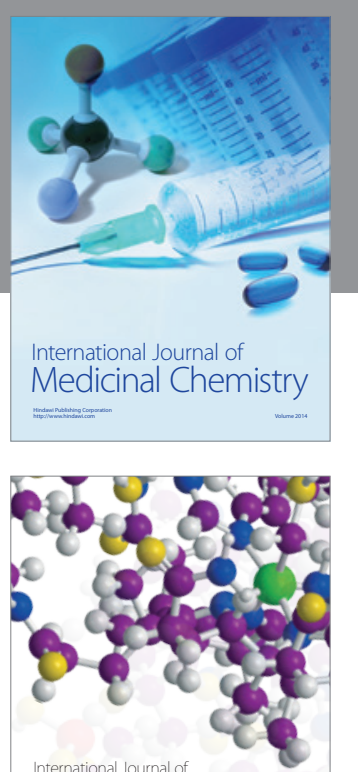

Carbohydrate Chemistry

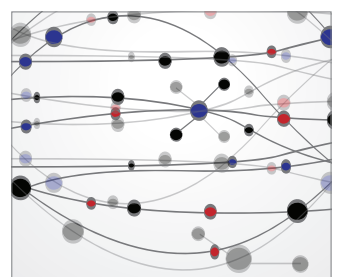

The Scientific World Journal
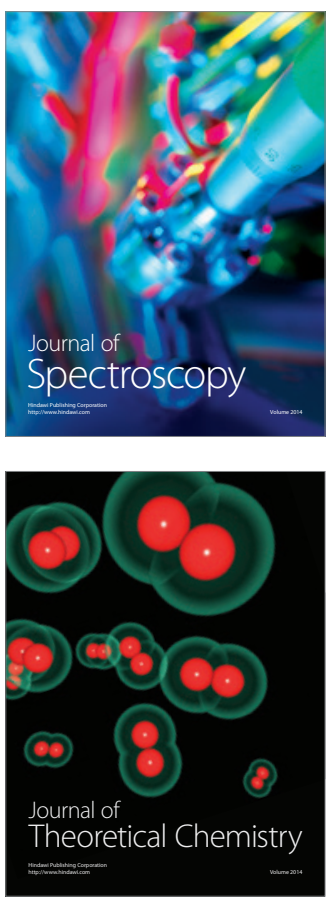
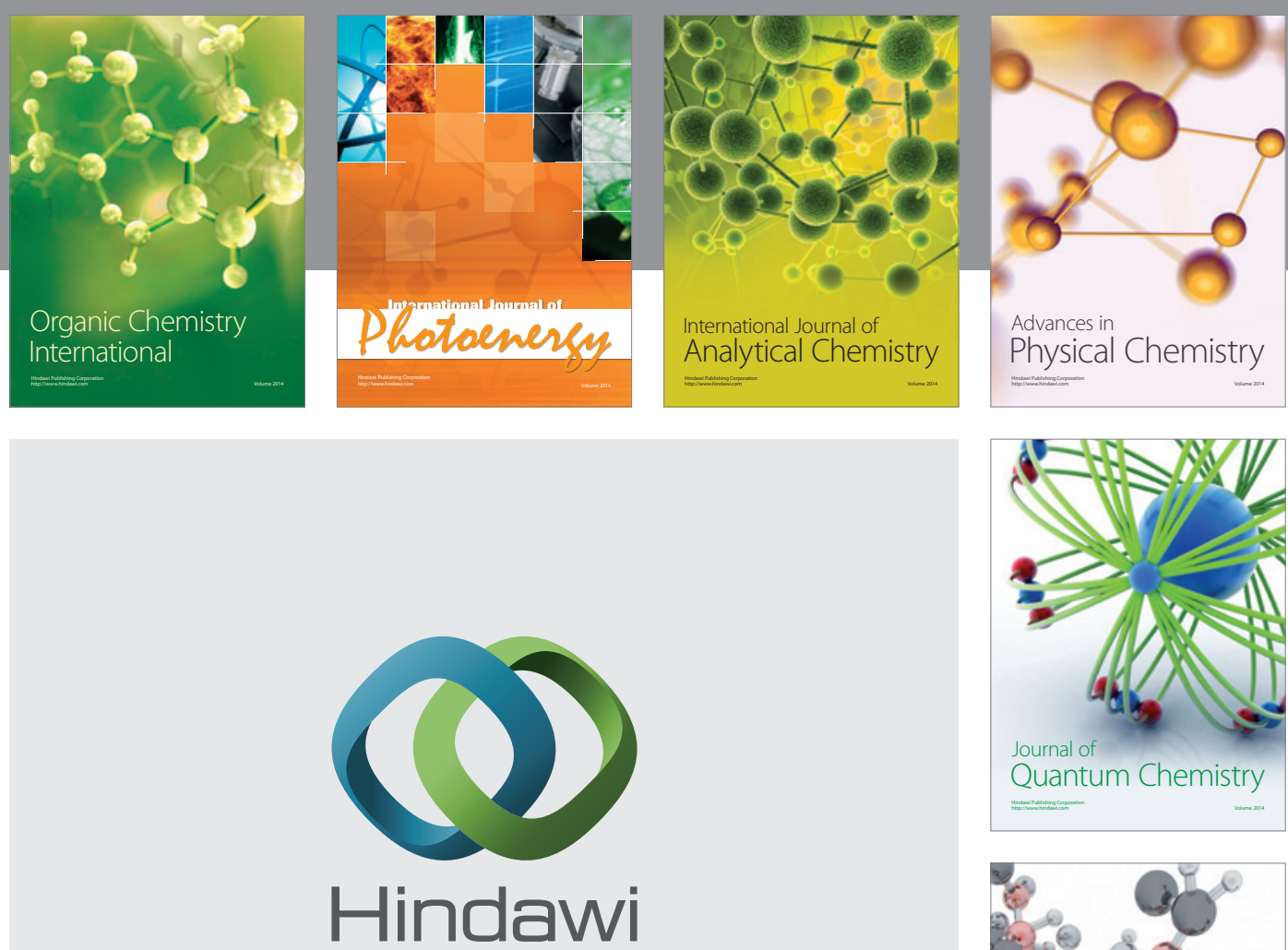

Submit your manuscripts at

https://www.hindawi.com

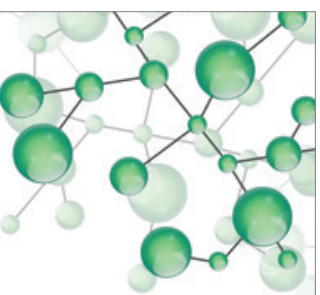

International Journal of

Inorganic Chemistry
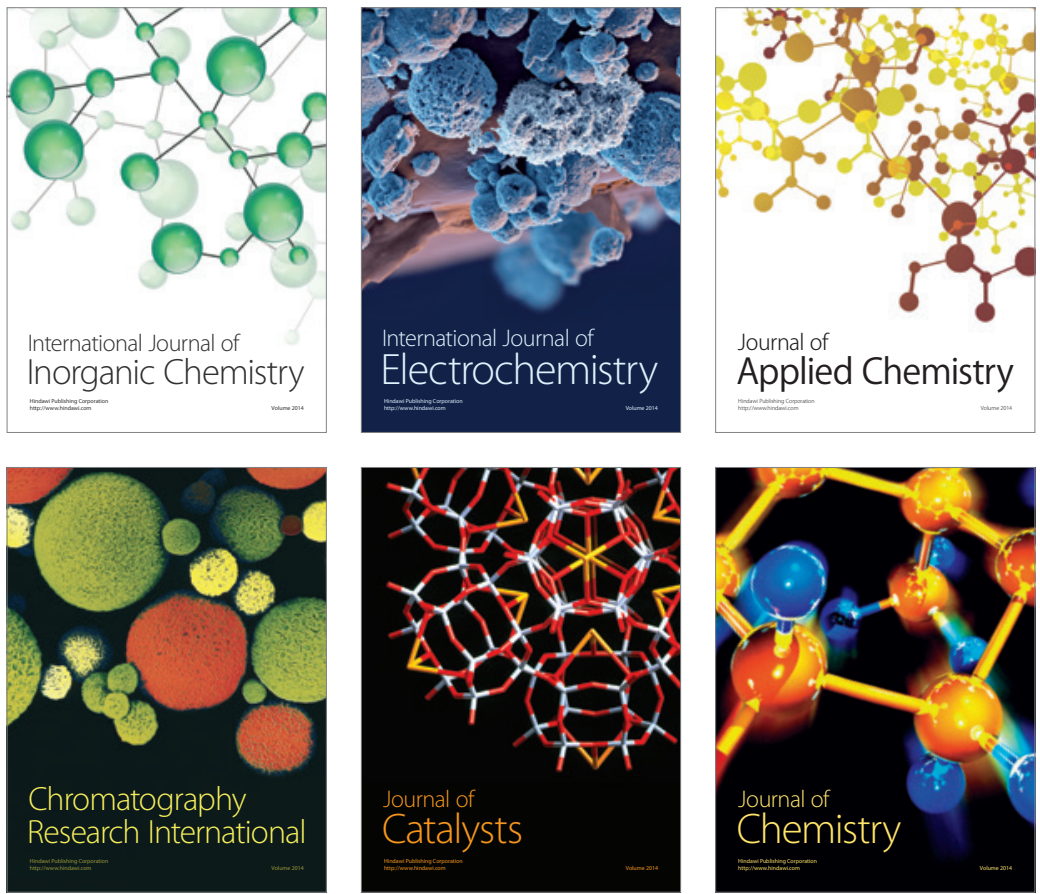

Journal of

Applied Chemistry
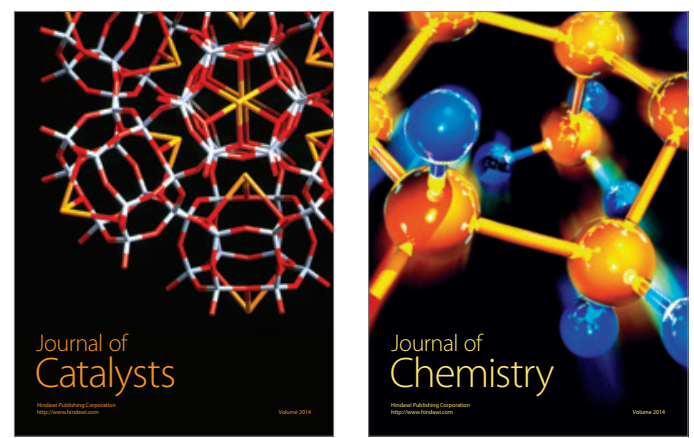
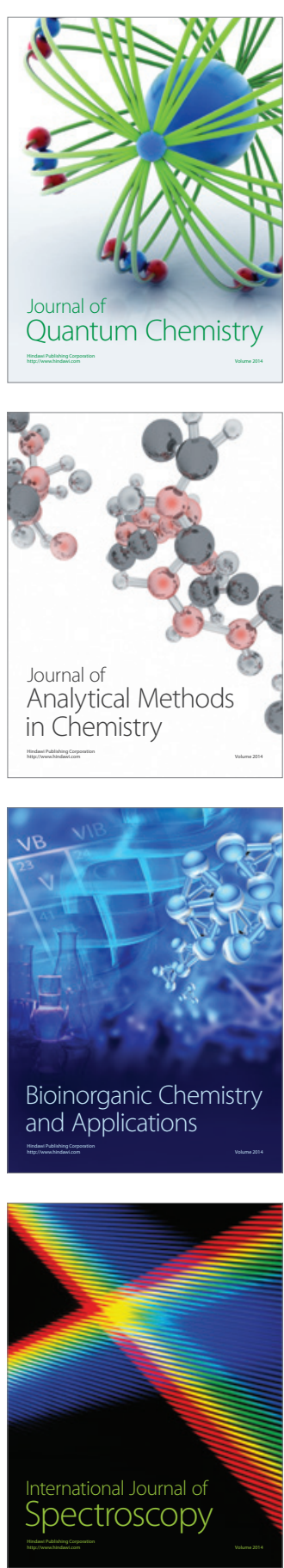